\title{
The effects of S-nitrosylation-induced PPAR $\gamma /$ SFRP5 pathway inhibition on the conversion of non-alcoholic fatty liver to non-alcoholic steatohepatitis
}

\author{
Hongyun Wang, Fengxia Li, Jing Feng, Junping Wang, Xiaobing Liu \\ Gastroenterology Department, Shanxi Provincial People's Hospital, Taiyuan, China \\ Contributions: (I) Conception and design: H Wang, F Li; (II) Administrative support: J Feng; (III) Provision of study materials or patients: H Wang, \\ F Li, J Wang, X Liu; (IV) Collection and assembly of data: All authors; (V) Data analysis and interpretation: J Feng, J Wang, X Liu; (VI) Manuscript \\ writing: All authors; (VII) Final approval of manuscript: All authors. \\ Correspondence to: Hongyun Wang. Gastroenterology Department, Shanxi Provincial People's Hospital, 29 Shuangta Si Street, Yingze District, \\ Taiyuan, China. Email: whysci0626@163.com.
}

Background: Peroxisome proliferators-activated receptors $\gamma(\operatorname{PPAR} \gamma)$ and secreted frizzled related protein 5 (SFRP5) are abnormally expressed in liver cells. But their role in the transformation of non-alcoholic fatty liver (NAFL) to non-alcoholic steatohepatitis (NASH) remains to be studied. We aimed to explore the role of S-nitrosylation (SNO) in the conversion of NAFL to NASH via the peroxisome PPAR $\gamma / \mathrm{SFRP} 5$ pathway.

Methods: A normal diet and methionine-choline deficient diet were used to construct the NAFL and NASH mouse models, respectively. The differences between the SNO of PPAR $\gamma$ in both models were measured by irreversible biotinylation. Quantitative reverse transcription PCR (qRT-PCR) and Western blotting were used to detect the effect of SNO on the expression of PPAR $\gamma$ messageRNA (mRNA) and protein in L02 hepatocytes. Nubiscan software, luciferase reporter gene, and chromatin immunoprecipitation assay (CHIP) were used to verify the targeting relationship between PPAR and SFRP5. The expression of tumor necrosis factor $\alpha$ (TNF $\alpha$ ), interleukin-1 $\beta$ (IL-1 $\beta$ ), and interleukin-6 (IL-6), which are indicators for the activation of Kupffer cells, were determined by enzyme linked immunosorbent assay (ELISA) after co-cultivation of L02 hepatocytes and Kupffer macrophages, as well as the exogenous regulation of SNO, PPAR $\gamma$, and SFRP5 in hepatic L02 cells.

Results: The NAFL and NASH mouse models were successfully constructed, and the level of PPAR $\gamma$ SNO in the NAFL model was significantly lower than the NASH model $(\mathrm{P}<0.05)$. The level of PPAR $\gamma$ was significantly downregulated after increasing the SNO of L02 cells, respectively $(\mathrm{P}<0.05)$. Nubiscan software and CHIP confirmed that PPAR $\gamma$ could bind to the promoter region of SFRP5 $(\mathrm{P}<0.05)$. Overexpression of PPAR $\gamma$ and SFRP5 could significantly downregulate the expression of TNF $\alpha$, IL-1 $\beta$, and IL-6 $(\mathrm{P}<0.05)$ correspondingly, while increasing the SNO level of L02 cells could restore the expression levels of TNF $\alpha$, IL-1 $\beta$, and IL-6.

Conclusions: SNO promoted the activation of macrophage Kupffer cells by inhibiting the PPAR $\gamma / \mathrm{SFRP} 5$ pathway in L02 hepatocytes, thereby promoting the conversion of NAFL into NASH.

Keywords: Non-alcoholic fatty liver (NAFL); non-alcoholic steatohepatitis (NASH); S-nitrosylation (SNO); peroxisome proliferators-activated receptors $\gamma$ (PPAR $\gamma$ ); secreted frizzled related protein 5 (SFRP5)

Submitted Feb 04, 2021. Accepted for publication Apr 17, 2021.

doi: $10.21037 / \mathrm{atm}-21-1070$

View this article at: http://dx.doi.org/10.21037/atm-21-1070 


\section{Introduction}

Non-alcoholic fatty liver disease (NAFLD) is the most common cause of chronic liver disease in the world. It is expected to become the most common indication for liver transplantation by 2030 and is also considered to be a risk factor for cardiovascular disease $(1,2)$. NAFLD can develop from benign non-alcoholic fatty liver (NAFL) to more severe non-alcoholic steatohepatitis (NASH). Nearly $25 \%$ of NASH patients could develop cirrhosis, and some of them could even progress to liver cancer $(3,4)$. Clarifying the key links and molecular mechanisms of NAFL's progression towards NASH will provide potential drug targets and treatment strategies for reversing NASH. It is currently believed that the abnormal activation of Kupffer cells, an intrinsic macrophage of the liver, is the core link leading to lobular inflammation (5), and the occurrence of hepatic lobular inflammation is the main pathological manifestation that differentiates NASH from NAFL (6). Therefore, exploring the molecular mechanism of abnormal activation of Kupffer cells has become the focus of current research to reverse NASH.

SFRP5 belongs to the SFRP family and contains a cysteine-rich domain homologous to the wingless/ integrated (Wnt) binding site (7). A large number of studies have shown that the c-Jun N-terminal kinase (JNK) and nuclear transcription factor $-\kappa \mathrm{B}(\mathrm{NF}-\kappa \mathrm{B})$ pathways are classic inflammatory pathways that can be activated by Kupffer cells during the conversion of NAFL to NASH (8). PPAR $\gamma$ is one of the members of the peroxisome Proliferator-Activated Receptor (PPAR) subfamily encoding nuclear receptors (9). A recent study showed that the expression level of PPAR $\gamma$ in liver cells under NASH was significantly lower than that in normal and NAFL states, which is consistent with the expression change of SFRP5, and the down-regulation of PPAR $\gamma$ expression mediated the occurrence of liver inflammation $(10,11)$. It is suggested that PPAR $\gamma$ and SFRP5 may participate in the transformation of NAFL to NASH by mediating Kupffer cell activation. We present the following article in accordance with the ARRIVE reporting checklist (available at http://dx.doi. org/10.21037/atm-21-1070).

\section{Methods}

\section{Cell lines, laboratory animals, and reagents}

Human normal L02 liver cells and macrophage Kupffer cells were purchased from American ATCC Company
(USA). Ob/Ob mice were purchased from Nanjing Junke Bioengineering Co., Ltd. (China). Short hairpin RNAperoxisome proliferators-activated receptors $\gamma /$ pcDNA3.1peroxisome proliferators-activated receptors $\gamma$ (sh-PPAR $\gamma /$ pcDNA3.1-PPAR $\gamma$ ) and Short hairpin RNA- secreted frizzled related protein 5/pcDNA3.1-secreted frizzled related protein 5 (sh-SFRP5/pcDNA3.1-SFRP5) were constructed in Guangzhou Huijun Biotechnology Co., Ltd. (China) Dulbecco's Modified Eagle Medium (DMEM), fetal bovine serum, penicillin, and streptomycin were purchased from American HYCLONE company (USA). Transient transfection kits, Lipofectamine 2000, Trizol, and PrimeScript ${ }^{\mathrm{TM}}$ reverse transcription PCR (RT-PCR) kits were purchased from Thermo Fisher (United States). The protein extraction kit, butyleyanoacrylate (BCA) protein concentration determination kit, and SDS-polyacrylamide gel electrophoresis (SDSPAGE) rapid preparation kit were purchased from Beijing Solable Technology Co., Ltd. (China). Maleimide biotin was purchased from Wuhan Aimeijie Technology Co., Ltd. (China) PPAR $\gamma$, SFRP5 primary and secondary antibodies and CHIP kits were purchased from Abcam (UK), and ELISA kits were purchased from R \& D Systems (USA).

\section{Construction of NAFL and NASH animal models}

$\mathrm{Ob} / \mathrm{Ob}$ mice were randomly divided into NAFL and NASH groups. NAFL group ob/ob mice were fed a normal diet, while NASH mice were fed with methionine and choline deficent (MCD). Normal diet formulas included L-amino acid $175.7 \mathrm{~g} / \mathrm{kg}$, maize starch $150.0 \mathrm{~g} / \mathrm{kg}$, sucrose $441.9 \mathrm{~g} / \mathrm{kg}$, cellulose $30.0 \mathrm{~g} / \mathrm{kg}$, dextrose maltose $50.0 \mathrm{~g} / \mathrm{kg}$, sodium bicarbonate $7.4 \mathrm{~g} / \mathrm{kg}$, corn oil $100.0 \mathrm{~g} / \mathrm{kg}$, vitamin mixture $10.0 \mathrm{~g} / \mathrm{kg}$, salt mixture $35.0 \mathrm{~g} / \mathrm{kg}$, choline $2 \mathrm{~g} / \mathrm{kg}$, and methionine $3 \mathrm{~g} / \mathrm{kg}$. The MCD diet was identical to the normal diet, but with the choline and methionine removed. Mice serum was collected for alanine transaminase (ALT), aspartate transaminase (AST), high density lipoprotein cholesterol (HDL-C), low density lipoprotein cholesterol (LDL-C), triglyceride (TG) and total cholesterol (TC) test to verify the success of the mouse model. Experiments were performed under a project license (No.: SYXK20190003 ) granted by institutional ethics committee of Shanxi Provincial People's Hospital, in compliance with institutional guidelines for the care and use of animals.

\section{Cell culture}

For the human normal L02 hepatocyte culture, L02 was 
cultured in DMEM containing 1\% penicillin and $10 \%$ fetal bovine serum, and was placed in an incubator at $37^{\circ} \mathrm{C}$ with $5 \%$ carbon dioxide $\left(\mathrm{CO}_{2}\right)$. To co-culture the human normal L02 hepatocytes and macrophage Kupffer cells, human normal L02 hepatocytes in the logarithmic growth phase of each treatment group were first trypsinized and digested. Next, the cells were centrifuged, resuspended in DMEM medium, and counted before use. The supernatant was then discarded from the six-well plate that was covered with macrophage Kupffer cells. The cells were then washed twice with phosphate buffer saline (PBS), and $2 \mathrm{~mL}$ of DMEM medium was then added to the plate. The incubated transwell chamber was then placed in the six-well plate, and $1.5 \mathrm{~mL}$ (containing $1 \times 10^{6}$ cells) of L02 cell suspension was added to the upper chamber. DMEM medium without Kupffer cells in the lower chamber was used as the control.

\section{Cell transfection}

Human normal L02 liver cells in the logarithmic growth phase were inoculated in 96-well plates, and the transfection process was carried out according to the instructions of the Lipofectamine 2000 kit. Specifically, after the transfection concentration was adjusted to $50 \mathrm{nmol} / \mathrm{L}$, sh-PPAR $\gamma /$ pcDNA3.1-PPAR $\gamma$ sh-SFRP5/pcDNA3.1-SFRP5, and a negative control were transfected into the L02 cells respectively, and were designated specifically as the NC group, sh-PPAR $\gamma$ group, pcDNA3.1-PPAR $\gamma$ group, shSFRP5 group, and the pcDNA3.1-SFRP5 group. $24 \mathrm{~h}$ after transfection, the transfection effect of the L02 cells was examined under a fluorescent microscope.

\section{Expression level of PPARy mRNA in human normal L02 liver cells was measured with $q R T-P C R$}

The total RNA of human normal L02 liver cells was extracted according to the instructions of the Trizol kit. After measuring the total RNA concentration, $0.97 \mu \mathrm{g}$ of total RNA was taken and reverse-transcribed according to the PrimeScriptTM RT reagent kit instructions to generate complementary DNA (cDNA). Real-time PCR was then carried out according to the SYBR ${ }^{\circledast}$ Green Realtime PCR Master Mix kit Manual. The qPCR reaction system $(20 \mu \mathrm{L})$ included $2 \mu \mathrm{L}$ cDNA, $0.8 \mu \mathrm{L}$ of the forward primer, $0.8 \mu \mathrm{L}$ of the reverse primer, $10 \mu \mathrm{L}$ SYBR Green Mix, $0.4 \mu \mathrm{L}$ ROX reference dye, and $6 \mu \mathrm{L} \mathrm{H}_{2} \mathrm{O}$. The qPCR reaction (40 cycle total) conditions were as follows: $50{ }^{\circ} \mathrm{C}$ heating for $2 \mathrm{~min}$, followed by $95^{\circ} \mathrm{C}$ pre- denaturation for $10 \mathrm{~min}$, followed by $95^{\circ} \mathrm{C}$ denaturation for $15 \mathrm{~s}$, and eventually $60^{\circ} \mathrm{C}$ annealing for $1 \mathrm{~min}$. The qPCR primer sequences used in this study were as follows: U6F: forward 5'-CTTCGGCAGCACATATACTAAAAT-3', reverse 5'-AATATGGAACGCTTCACGA-3'; PPAR $\gamma$ : forward 5'-TGGTGTACGATCACTGCGAC-3', reverse 5'-CACTTCTGGAAGCGGCAGTA-3'. U6 was used as an internal reference, the fluorescence signal and cycle threshold $(\mathrm{Ct})$ value were detected with the icycler software of BIO-RAD (BIO-RAD, USA), and the expression level of PPAR $\gamma$ mRNA was calculated by the $2^{-\Delta \Delta \mathrm{Ct}}$ method.

\section{Expression level of PPAR protein in human normal L02 liver cells was measured by Western blotting}

Radio Immunoprecipitation Assay (RIPA) was used to separately lyse cells and tissues to extract total protein. The BCA method was used to measure the protein concentration before determining the sample volume per well. The samples were separated by SDS-PAGE and transferred to a polyvinylidene fluoride membrane, and then blocked with $5 \%$ skimmed milk powder for $1 \mathrm{~h}$. Subsequently, the primary antibodies, PPAR $\gamma(1: 1,000)$ and SFRP5 $(1: 1,000)$, were added and incubated overnight at $4{ }^{\circ} \mathrm{C}$. Next, the primary antibodies were removed and the corresponding secondary antibodies, PPAR $\gamma(1: 2,000)$ and SFRP5 $(1: 2,000)$, were added and blocked at room temperature for $1 \mathrm{~h}$. The DAB reagent was then added for image development. Using glyceraldehyde-3-phosphate dehydrogenase (GAPDH) as an internal reference, the protein band was quantitatively analyzed with Image J software (U.S. State Health Center, USA).

\section{Level of S-nitrosylation (SNO) of PPARy in buman normal liver cells was measured by irreversible biotinylation}

Cells were lysed with RIPA solution, mixed, and centrifuged. The supernatant was then taken and s-methyl methanethiosulfonate (MMTS) was added. Protein from each treatment group was resuspended, reacted at $50{ }^{\circ} \mathrm{C}$ for $30 \mathrm{~min}$, and shaken every $4 \mathrm{~min}$. Subsequently, two volumes of ice-acetone were added, and the samples were reacted at $-20{ }^{\circ} \mathrm{C}$ for $10 \mathrm{~min}$, and after centrifugation, the excess MMTS was discarded. The obtained protein was then resuspended in Hens buffer, and $0.2 \mathrm{mmol} / \mathrm{L}$ maleimide biotin and $10 \mathrm{mmol} / \mathrm{L}$ ascorbate were added, which was then reacted at room temperature for $1 \mathrm{~h}$. 
Excess biotin was removed after precipitation with acetone. The sample was then boiled in Hens buffer containing $200 \mathrm{mmol} / \mathrm{L}$ dithiothreitol (DTT) for $15 \mathrm{~min}$ to remove potential disulfide bonds between molecules. After that, the neutralization reaction was carried out, and the biotinylated protein was purified and eluted. Western blotting was then used to detect the SNO level of PPAR $\gamma$.

\section{Dual-luciferase reporter gene experiment}

pGL-SFRP5 containing different truncated lengths of the SFRP5 promoter region and Renilla luciferase reporter plasmid were transfected into L02 cells according to the instructions of the Lipofectamine 2000 kit. $24 \mathrm{~h}$ after transfection of the pGL-3-2284 containing the SFRP5 promoter region and Renilla luciferase reporter plasmid, the cells were divided into dimethyl sulfoxide (DMSO) group, PPAR $\gamma$ antagonist (GW9662) group, Rosiglitazone (RSG) group, Adenovirus-PPAR $\gamma$ (AD-PPAR $\gamma$ ) group, and RSG $+\mathrm{AD}-\mathrm{PPAR} \gamma$ group, and treated with the $\operatorname{PPAR} \gamma$ agonist, rosiglitazone, as well as the $\operatorname{PPAR} \gamma$ agonist rosiglitazone + adenovirus that overexpresses PPAR $\gamma$. Following the treatments, the relative activity of luciferase was expressed by the ratio of firefly luciferase activity and renal luciferase activity according to the instructions of the dual-luciferase reporter gene kit.

\section{The targeting relationship between PPARy and SFRPS was verified by Nubiscan software and CHIP}

The Nubiscan online software was used to predict the binding site of the SFRP5 promoter region, and a similarity score greater than 0.8 was used as the inclusion criterion. Normal human L02 hepatocytes in the logarithmic growth phase were taken and $1 \%$ formaldehyde was used for cell fixation. After standing at $37^{\circ} \mathrm{C}$ for $10 \mathrm{~min}$, glycine with a final concentration of $0.125 \mathrm{M}$ was then added. After mixing, the cells were then placed at room temperature for $5 \mathrm{~min}$ to end the fixation. After fixation, the medium was discarded, the cells were washed with cold PBS three times, and the cells were then scraped into a $15 \mathrm{~mL}$ eppondorf (EP) tube and centrifuged at $800 \times \mathrm{g}$ for $5 \mathrm{~min}$ to collect the cells. After centrifugation, $0.5 \mathrm{ml}$ of cell lysis buffer was added to resuspend the cells. The cells were then sonicated, the sonication solution was centrifuged at 2,000 $\times \mathrm{g}$ for $5 \mathrm{~min}$, and the supernatant was then transferred to a new EP tube to precipitate the DNA fragment. PPAR $\gamma$ antibody and immunoglobulin G (IgG) antibody were then added to the supernatant, $10 \%$ of the final solution was taken, and Protein A magnetic beads were added and mixed with the solution. Protein/DNA complexes were collected after $12 \mathrm{~h}$ of incubation at $4^{\circ} \mathrm{C}$, and DNA was purified using a gel recovery kit. QRT-PCR was then used to determine the enrichment of PPAR $\gamma$ protein in the promoter region of the SFRP5 gene.

\section{The expression levels of TNF,$I L-1 \beta$, and $I L-6$ secreted by macrophages detected with ELISA}

The Kupffer cell supernatant of each treatment group was collected by centrifugation at $1,000 \mathrm{r} / \mathrm{min}$. After centrifugation for $5 \mathrm{~min}$ the supernatant was collected. The concentration of TNF $\alpha$, IL-1 $\beta$, and IL- 6 in the culture supernatant was then determined according to the instructions of the ELISA kit. Specifically, the concentrations of TNF $\alpha$, IL-1 $\beta$, and IL- 6 were calculated based on a standard curve associating the standard concentration and absorbance (A) value.

\section{Statistical analysis}

The experimental data were analyzed with SPSS 20.0 statistical software (IBM, New York, USA), and the figures were drawn with Graphpad 8.0 software (GraphPad Software, USA). The t-test was used for comparison between groups, and single-factor analysis of variance was used for comparison among multiple groups. $\mathrm{P}<0.05$ was used to indicate a statistically significant difference.

\section{Results}

\section{Successfully constructed NAFL and NASH mouse models}

As shown in Table 1, we first detected ALT, AST, HDL-C, LDL-C, TG and TC in the serum of the constructed NAFL and NASH mice models. Compared with normal mice, the serum levels of ALT, AST, LDL-C, TG and TC in NAFL mice were significantly increased, while HDL-C was significantly decreased $(\mathrm{P}<0.05)$. In addition, the levels of ALT, AST, LDL-C, TG and TC in the serum of NASH mice were significantly higher than those of NAFL mice, while the levels of HDL-C were the opposite $(\mathrm{P}<0.05)$. According to the above data, we have successfully constructed NAFL and NASH mouse models. 
Table 1 Comparison of biochemical indexes among each groups of mice

\begin{tabular}{lccc}
\hline & NC & NAFL & NASH \\
\hline ALT (U/L) & $22.14 \pm 4.21$ & $57.61 \pm 6.41^{*}$ & $91.87 \pm 11.19^{\#}$ \\
AST (U/L) & $34.11 \pm 5.72$ & $61.77 \pm 8.52^{*}$ & $89.16 \pm 7.81^{\#}$ \\
HDL-C (mmol/L) & $0.89 \pm 0.26$ & $0.46 \pm 0.28^{\star}$ & $0.27 \pm 0.09^{\#}$ \\
LDL-C (mmol/L) & $2.81 \pm 0.57$ & $4.59 \pm 1.33^{*}$ & $6.94 \pm 1.12^{\#}$ \\
TG (mmol/L) & $0.86 \pm 0.32$ & $2.56 \pm 0.83^{*}$ & $5.67 \pm 1.19^{\#}$ \\
TC $(\mathrm{mmol} / \mathrm{L})$ & $1.92 \pm 0.49$ & $6.84 \pm 1.57^{\star}$ & $9.69 \pm 1.99^{\#}$ \\
\hline
\end{tabular}

${ }^{*} \mathrm{P}<0.05$ vs. NC group; ${ }^{\mathrm{P}}<0.05$ vs. NAFL group. NC, negative control; NAFL, non-alcoholic fatty liver; NASH, non-alcoholic steatohepatitis; ALT, alanine transaminase; AST, aspartate transaminase; HDL-C, high density lipoprotein cholesterol; LDL-C, low density lipoprotein cholesterol; TG, triglyceride; TC, total cholesterol.

\section{SNO levels of PPARy in NAFL and NASH mouse models}

Western blotting results showed that the expression level of PPAR $\gamma$ in the NASH mouse model increased significantly compared with the NAFL group $(\mathrm{P}<0.05$, Figure $1 A)$. The expression level of SNO-PPAR $\gamma$ in the NAFL mouse model was significantly lower than that of the NASH mouse model $(\mathrm{P}<0.05$, Figure $1 B)$. Also, the expression level of inducible nitric oxide synthase (iNOS) in the NAFL mouse model was significantly lower than that of the NASH mouse model $(\mathrm{P}<0.05$, Figure 1C). These results indicated that the SNO level of PPAR $\gamma$ in NASH mice was abnormally higher than that in NAFL mice.

\section{The effect of SNO on the expression of PPAR protein and $m R N A$ in L02 bepatocytes}

Western blotting results showed that after SNO enhancer S-Nitrosoglutathione (GSNO) and inhibitor 1,400 W treatment of L02 hepatocytes, the expression level of the PPAR $\gamma$ protein in the GSNO group was significantly lower than that in the NC group, while the expression level of the PPAR $\gamma$ protein in the $1,400 \mathrm{~W}$ group was significantly higher than that in the $\mathrm{NC}$ group $(\mathrm{P}<0.05$, Figure $2 A$ ). Consistent with this, the $\mathrm{qRT}-\mathrm{PCR}$ results showed that the expression level of PPAR $\gamma$ mRNA in the GSNO group was significantly lower than that in the NC group, and the expression level of PPAR $\gamma$ mRNA in the $1,400 \mathrm{~W}$ group was significantly higher than that in the $\mathrm{NC}$ group $(\mathrm{P}<0.05$, Figure $2 B)$. As expected, compared with the NC group, the expression level of SNO-PPAR $\gamma$ protein in the GSNO group was significantly increased, while the expression level of SNO-PPAR $\gamma$ protein in the $1,400 \mathrm{~W}$ group was significantly down-regulated $(\mathrm{P}<0.05)$,
Figure 2C. The expression of SNO-PPAR $\gamma$ mRNA in the GSNO group was significantly higher than that in the NC group, while the $1,400 \mathrm{~W}$ group was significantly lower than that in the $\mathrm{NC}$ group $(\mathrm{P}<0.05)$, Figure $2 D$. Also, the protein expression levels of adiponectin and adapter protein2 (ap2), which are the target genes of PPAR $\gamma$ in the GSNO group, were significantly higher than those of the NC group. Not surprisingly, the protein expression levels of adiponectin and ap2 in the $1,400 \mathrm{~W}$ group were significantly lower than those of the $\mathrm{NC}$ group $(\mathrm{P}<0.05$, Figure 2E). As expected, the mRNA expression levels of adiponectin and ap2 in the GSNO group were significantly higher than those in the NC group, while the mRNA expression levels of the adiponectin and ap2 proteins in the $1,400 \mathrm{~W}$ group were significantly lower than those in the $\mathrm{NC}$ group $(\mathrm{P}<0.05$, Figure $2 F)$. These results indicated that $\mathrm{SNO}$ modification can down-regulate the expression levels of the PPAR $\gamma$ protein and mRNA in L02 hepatocytes.

\section{Verification of the targeting relationship between PPARy and SFRP5}

Nubiscan online software was used to predict the binding site of the SFRP5 promoter region (with a similarity score greater than 0.8 as the inclusion criterion). The SFRP5 promoter region contains three potential binding sites for PPAR $\gamma$, as shown in Table 2. Luciferase reporter gene results showed that the relative fluorescence values of pGLSFRP5 in different length groups were significantly higher than those in the pGL-3-Basic group $(\mathrm{P}<0.05$, Figure $3 A)$. Also, pGL-3-3000, pGL-3-2543, and pGL-3-2284 were significantly different from pGL-3-1500, pGL-3-1000, and pGL-3-500 $(\mathrm{P}<0.05$, Figure $3 A)$. On the other hand, there 

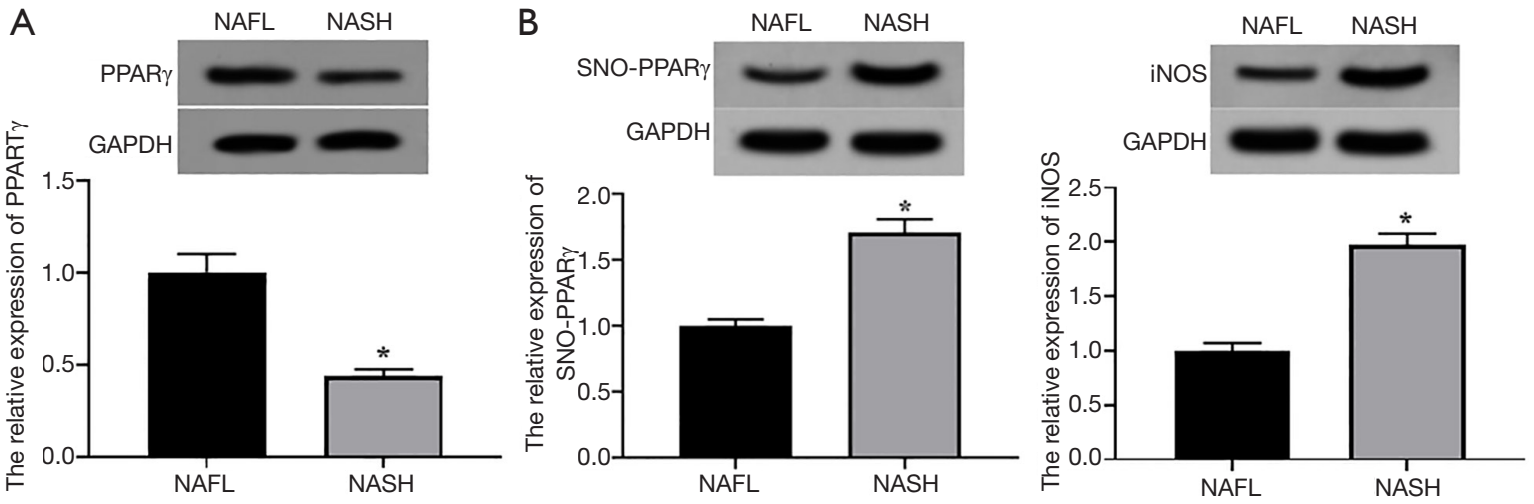

Figure 1 SNO levels of PPAR $\gamma$ in NAFL and NASH mouse models. (A) The expression levels of PPAR $\gamma$ in NAFL and NASH models. (B)The expression levels of SNO-PPAR $\gamma$ in NAFL and NASH models; (C) the expression levels of iNOS in NAFL and NASH models. ${ }^{*} \mathrm{P}<0.05$ NAFL vs. NASH group. PPAR $\gamma$, Peroxisome proliferators-activated receptors $\gamma$; SFRP5, secreted frizzled related protein 5; SNO, S-nitrosylation; iNOS, inducible nitric oxide synthase; NAFL, non-alcoholic fatty liver; NASH, non-alcoholic steatohepatitis.

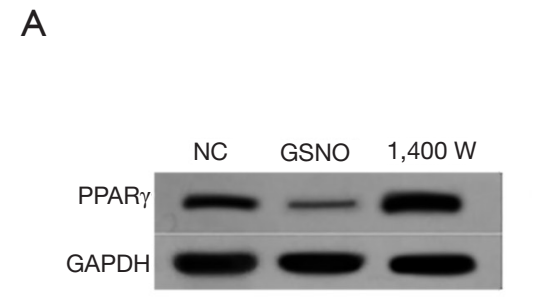

C
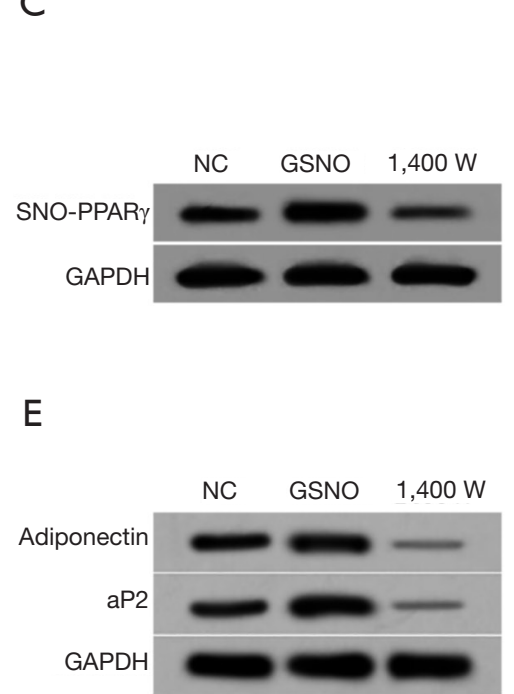
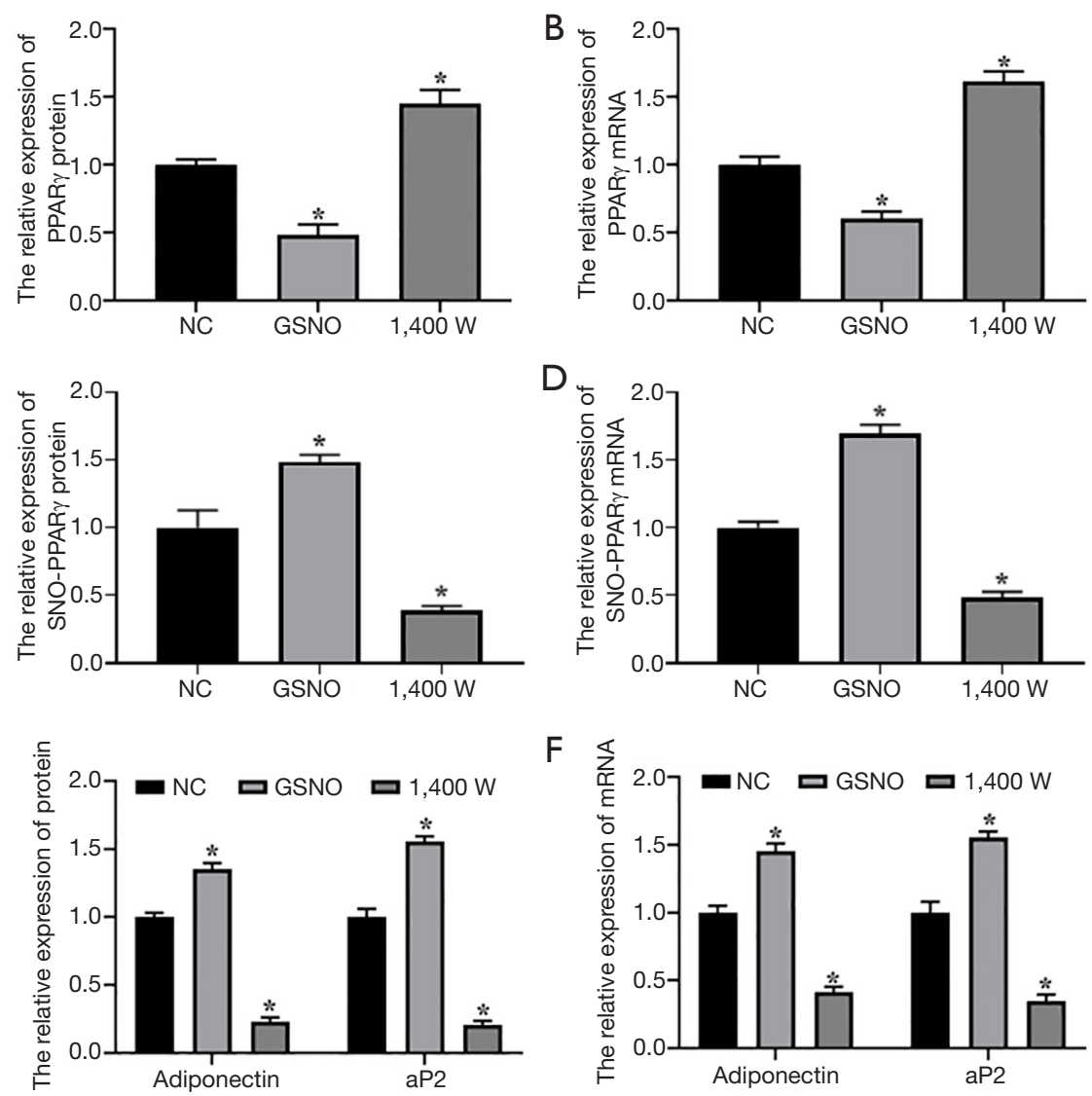

Figure 2 Effect of SNO on the expression of the PPAR $\gamma$ protein and mRNA in L02 hepatocytes. (A,B) The expression levels of the PPAR $\gamma$ protein and mRNA in L02 cells; (C,D) the expression levels of targeting gene of SNO-PPAR $\gamma$ protein and mRNA in L02 cells; (E,F) the expression levels of the target of the PPAR $\gamma$ protein and mRNA in L02 cells. Experimental vs. NC group, ${ }^{*} \mathrm{P}<0.05$. NC, negative control; NAFL, non-alcoholic fatty liver; NASH, non-alcoholic steatohepatitis; GSNO, SNO enhancer S-Nitrosoglutathione; PPAR $\gamma$, peroxisome proliferators-activated receptors $\gamma$; SNO, S-nitrosylation; ap2, adapter protein2. 
Table 2 Possible binding regions of PPAR $\gamma$ to the SFRP5 promoter

\begin{tabular}{lccc}
\hline Position & Score & $P$ value & Site sequence \\
\hline$-2,543$ & 0.811344 & 0.016892 & AGGGCAAGGGCTGACCA \\
$-2,529$ & 0.811344 & 0.016892 & TGACCACAGAAGGGCA \\
$-2,284$ & 0.803993 & 0.0139931 & TGCCAGCTCTGTCCAGGTCA \\
\hline
\end{tabular}

PPAR $\gamma$, peroxisome proliferators-activated receptors $\gamma$; SFRP5, secreted frizzled related protein 5 .

was no significant difference among pGL-3-3000, pGL-32543, pGL-3-2284, and pGL-3-1500, as well as between pGL-3-1000 and pGL-3-500, suggesting that there are important transcriptional activation cis response elements between $-2,284$ to $-1,500 \mathrm{bp}$. Furthermore, the luciferase activity in the GW9662 group was lower than that of the DMSO group, and the luciferase activity of the RSG + ADPPAR $\gamma$ group was higher than that of the DMSO group $(\mathrm{P}<0.05$, Figure 3B). Meanwhile, the luciferase activity of the RSG and AD-PPAR $\gamma$ groups was the same as that of the DMSO group, suggesting that PPAR $\gamma$ can enhance the activity of the SFRP5 promoter. Based on these luciferase reporter gene experiment results, primer 1 and primer 2 of the DNA that bound to PPAR $\gamma$ as a template were designed, and further results through CHIP experiments showed that PPAR $\gamma$ can bind to the SFRP5 promoter region, as shown in Figure 3C. Consistent with this, qRT-PCR results showed that the Fold Enrichment was increased by 16.4 times with SFRP5 after using the PPAR $\gamma$ antibody (Figure 3D). The above experiments showed that PPAR $\gamma$ can bind to the SFRP5 promoter region and enhance the activity of the SFRP5 promoter.

\section{The effect of SNO modification on the activation of macrophage Kupffer cells by regulating the PPARy/SFRP5 patbway in LO2 bepatocytes}

Western blotting results showed that the expression levels of PPAR $\gamma$ and SFRP5 proteins in L02 cells in the sh-PPAR $\gamma$ and sh-SFRP5 groups were significantly lower than those in the NC group, whereas the expression levels of PPAR $\gamma$ and SFRP5 proteins in L02 cells in the pcDNA-PPAR $\gamma$ and pcDNA-SFRP5 groups were significantly higher than those in the NC group $(\mathrm{P}<0.05$, Figure $4 A, B)$. ELISA results showed that after the co-culture of L02 hepatocytes with macrophage Kupffer cells, the expression levels of TNF $\alpha$, IL-1 $\beta$, and IL-6 secreted by Kupffer cells in the GSNO and 1,400 W groups were significantly higher and lower than those in $\mathrm{NC}$ group, respectively $(\mathrm{P}<0.05$, Figure $4 C, D)$. Moreover, the expression levels of $\mathrm{TNF} \alpha$, IL- $1 \beta$, and IL- 6 secreted by Kupffer cells in the pcDNAPPAR $\gamma$ and pcDNA-SFRP5 groups were significantly lower than those in the NC group $(\mathrm{P}<0.05)$; however, the expression levels of TNF $\alpha$, IL-1 $\beta$, and IL- 6 secreted by Kupffer cells in the sh-PPAR $\gamma$ and sh-SFRP5 groups were significantly higher than those in the $\mathrm{NC}$ group $(\mathrm{P}<0.05$, Figure $4 C, D)$. On the other hand, the expression levels of TNF $\alpha$, IL- $1 \beta$, and IL- 6 secreted by Kupffer cells in the GSNO + pcDNA-PPAR $\gamma / \mathrm{SFRP} 5$ and $1,400 \mathrm{~W}+$ shPPAR $\gamma /$ SFRP5 groups were not significantly different from the control group. The above results indicated that SNO modification activated macrophage Kupffer cells by inhibiting the PPAR $\gamma / \mathrm{SFRP5}$ pathway in L02 cells, thereby promoting the conversion of NAFL to NASH.

\section{Discussion}

As mentioned above, the abnormal activation of Kupffer cells, the intrinsic macrophages of the liver, plays an important role in the conversion of NAFL to NASH. The activation of Kupffer cells is a complex biological process that is regulated by multiple factors and is related to intestinal-derived endotoxin, the space-occupying effect of hepatocyte steatosis, and toxic lipid metabolites (12). Also, regulation of Kupffer cell activation by cytokines produced by the paracrine of hepatocytes is also an important factor that promotes NASH (13).

Recent studies have found that SFRP5 can inhibit the binding of Wnt5a to its receptor, resulting in the inhibition of the Wnt pathway, which inhibits the activation of macrophages in fat, gastric mucosa, and other tissues $(14,15)$. One study also found that SFRP5 was highly expressed in hepatocytes, and the expression level of SFRP5 in the liver cells of NASH patients was abnormally lower than that of normal people and NAFL patients (16), suggesting that the abnormal activation of Kupffer cells could be due to the 
A

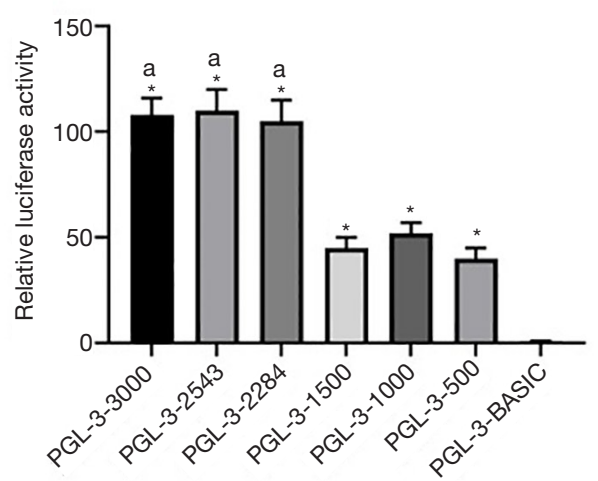

C

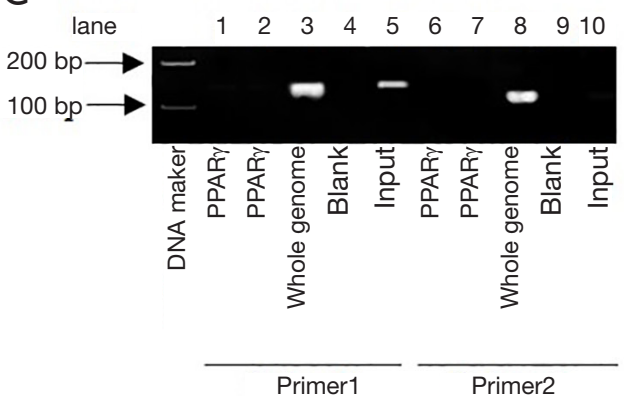

B
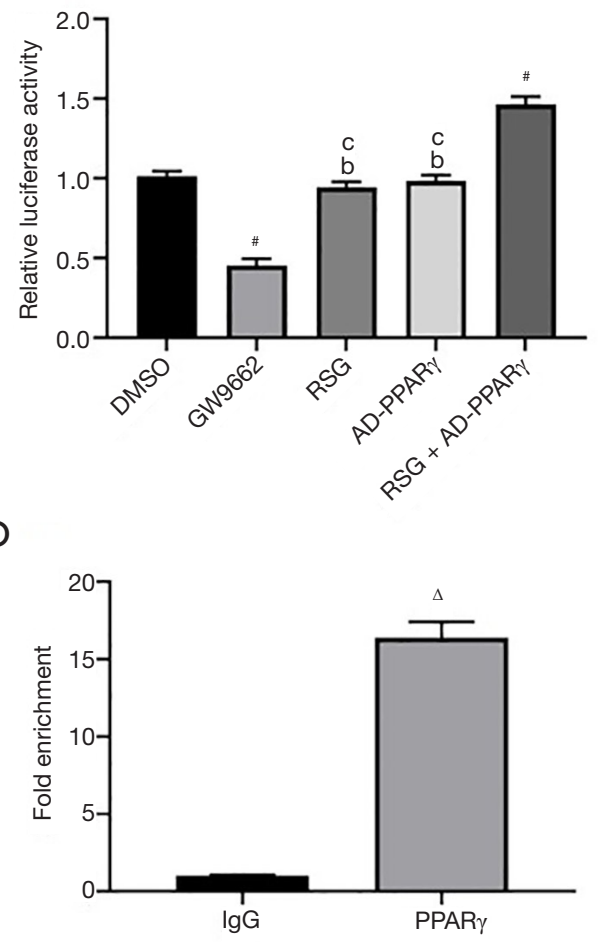

Figure 3 Verification of the targeting relationship between PPAR $\gamma$ and SFRP5. (A,B) Luciferase activity of each group; (C) the targeting relationship between PPAR $\gamma$ and SFRP5 was verified by CHIP; (D) fold enrichment of SFRP5. *P<0.05 vs. pGL-3-Basic group; aP $<0.05 v s$. pGL-3-1000 group; ${ }^{*} \mathrm{P}<0.05$ vs. DMSO group; $\mathrm{bP}<0.05$ vs. GW9662 group; $\mathrm{P}<0.05$ vs. RSG + AD-PPAR $\gamma$ group; ${ }^{\wedge} \mathrm{P}<0.05$ vs. IgG group. PPAR $\gamma$, peroxisome proliferators-activated receptors $\gamma$; DMSO, dimethyl sulfoxide; GW9662, PPAR $\gamma$ antagonist; RSG, rosiglitazone; AD, adenovirus.

decreased secretion of SFRP5 by liver cells, which could have important research significance in the progress of NASH.

At the same time, clinical trials have found that rosiglitazone (PPAR $\gamma$ agonist) can inhibit macrophage activation and improve liver inflammation in NASH patients (17). In addition, one study also found that during adipocyte differentiation, the expression changes of SFRP5 and PPAR $\gamma$ were completely congruent, and rosiglitazone could increase the expression of SFRP5 (18), suggesting that PPAR $\gamma$ may be an upstream regulatory gene of SFRP5. In this study, the luciferase reporter gene and CHIP experiments confirmed that PPAR $\gamma$ can bind to the SFRP5 promoter region and can enhance the SFRP5 promoter activity. Furthermore, overexpression or knockdown of PPAR $\gamma$ and SFRP5 can inhibit or promote the activation of Kupffer cells, thereby regulating the transformation of NAFL to NASH.

There are several ways to regulate $\operatorname{PPAR} \gamma$ expression, including transcriptional regulation, epigenetic modification, ubiquitination modification, and S-nitrosation modification $(19,20)$. SNO is a typical redox-dependent protein post-translational modification, which is closely related to the pathophysiological process of oxidative stress responses (21). In eukaryotic cells, NOS family proteins, especially inducible NOS (iNOS), are the main endogenous nitric oxide (NO) donors, which contribute to cellular SNO (22). Cumulative studies have shown that a large accumulation of iNOS and NO will promote protein SNO, which will participate in the occurrence and development of many diseases (23-25). In addition, studies have found that iNOS is the main NO synthase in hepatocytes, which has a high expression abundance in the cytoplasm (26), and PPAR $\gamma$ was initially expressed in the cytoplasm (27). Also, structural analysis found that there are 10 cysteine residues in the PPAR $\gamma$ protein, adipocytes, and bone marrow mesenchymal cells. Some of these cysteine residues can be modified by SNO, thereby reducing the expression 

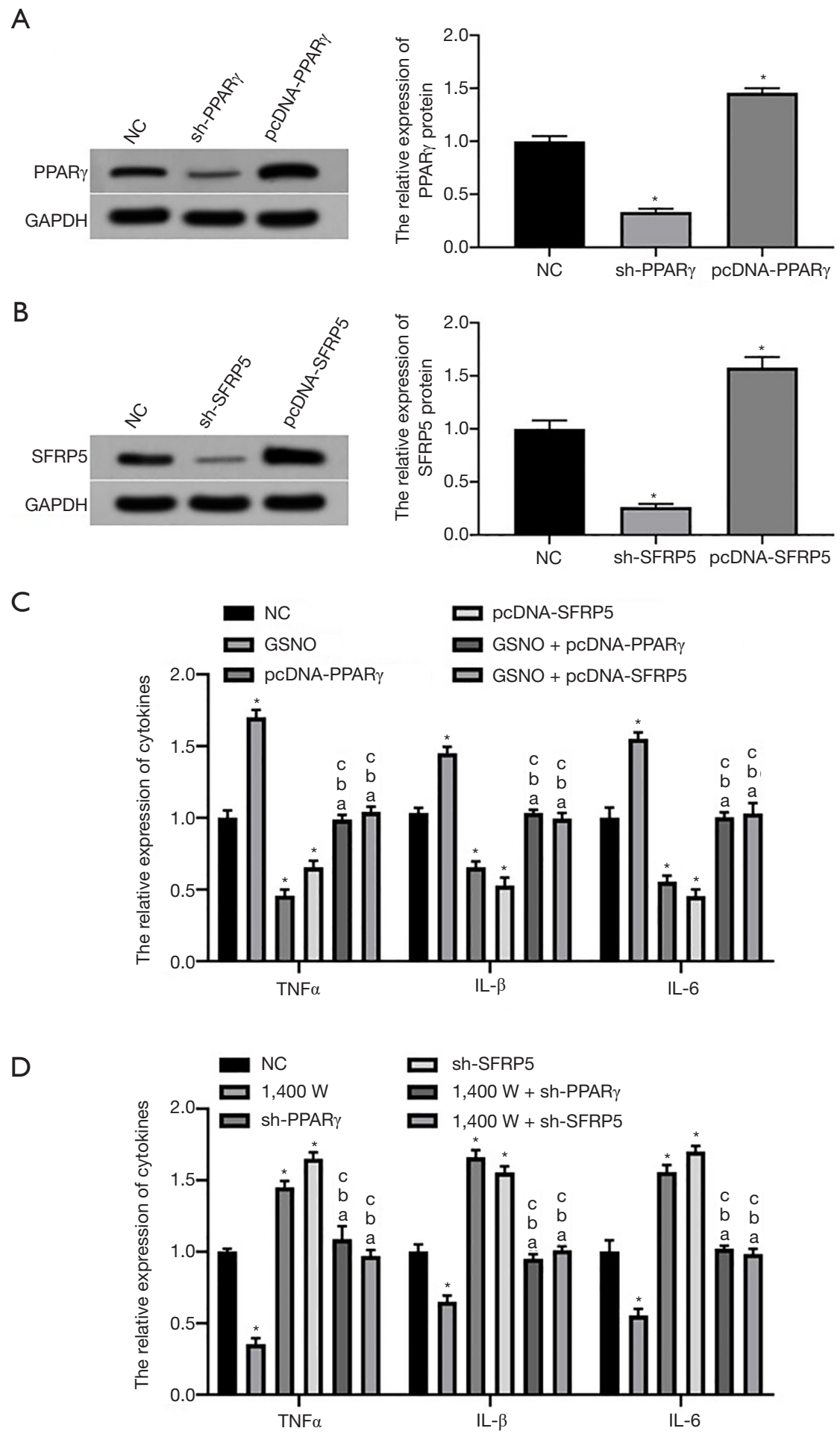

Figure 4 Effects of SNO on macrophage Kupffer activation by regulating PPAR $\gamma / \mathrm{SFRP} 5$ pathway in L02 hepatocytes. (A,B) The expression levels of PPAR $\gamma$ and SFRP5 protein in L02 cells; (C,D) the levels of TNF $\alpha$, IL-1 $\beta$, and IL-6 secreted by macrophage Kupffer cells. ${ }^{*} \mathrm{P}<0.05$ vs. NC group; $\mathrm{aP}<0.05$ vs. GSNO/1,400 W group; $\mathrm{bP}<0.05$ vs. pcDNA/sh-PPAR $\gamma$ group; $\mathrm{cP}<0.05$ vs. pcDNA/sh-SFRP5 group. NC, negative control; PPAR $\gamma$, peroxisome proliferators-activated receptors $\gamma$; SFRP5, secreted frizzled related protein 5; SNO, S-nitrosylation; GSNO, SNO enhancer S-Nitrosoglutathione; TNF $\alpha$, tumor necrosis factor $\alpha$; IL-1 $\beta$, interleukin-1 $\beta$; IL-6, interleukin-6. 
of PPAR $\gamma$ and transcriptional activity $(20,21)$. The abovementioned evidence suggests that PPAR $\gamma$ and iNOS have the same subcellular localization, and the SNO modification of PPAR $\gamma$ also has a spatial and structural basis. This study found that the use of ordinary diet and MCD feeding could construct NAFL and NASH mouse models, and through irreversible biotin detection, it was found that the level of SNO modification of PPAR $\gamma$ in NASH was significantly higher than that of NAFL. Moreover, cell experiments showed that SNO modification can down-regulate the expression levels of the PPAR $\gamma$ protein and mRNA in L02 liver cells. At the same time, enhancing or inhibiting SNO modification in L02 cells can in turn promote or inhibit Kupffer cell activation.

In summary, this study explored the effect of SNO modification on Kupffer cell activation via the PPAR $\gamma /$ SFRP5 pathway in L02 hepatocytes. The results in this study showed that SNO modification inhibited the expression levels of PPAR $\gamma$ and SFRP5 in L02 cells, thereby abnormally activating Kupffer cells, and thus, promoting the conversion of NAFL to NASH.

\section{Acknowledgments}

Funding: None.

\section{Footnote}

Reporting Checklist: The authors have completed the ARRIVE reporting checklist. Available at http://dx.doi. org/10.21037/atm-21-1070

Data Sharing Statement: Available at http://dx.doi. org/10.21037/atm-21-1070

Conflicts of Interest: All authors have completed the ICMJE uniform disclosure form (available at http://dx.doi. org/10.21037/atm-21-1070). The authors have no conflicts of interest to declare.

Ethical Statement: The authors are accountable for all aspects of the work in ensuring that questions related to the accuracy or integrity of any part of the work are appropriately investigated and resolved. Experiments were performed under a project license (No.: SYXK20190003) granted by institutional ethics committee of Shanxi Provincial People's Hospital, in compliance with institutional guidelines for the care and use of animals.
Open Access Statement: This is an Open Access article distributed in accordance with the Creative Commons Attribution-NonCommercial-NoDerivs 4.0 International License (CC BY-NC-ND 4.0), which permits the noncommercial replication and distribution of the article with the strict proviso that no changes or edits are made and the original work is properly cited (including links to both the formal publication through the relevant DOI and the license). See: https://creativecommons.org/licenses/by-nc-nd/4.0/.

\section{References}

1. Byrne CD, Targher G. NAFLD: a multisystem disease. J Hepatol 2015;62:S47-64.

2. Marcuccilli M, Chonchol M. NAFLD, and Chronic Kidney Disease. Int J Mol Sci 2016;17:562.

3. Eslam M, Valenti L, Romeo S. Genetics and epigenetics of NAFLD and NASH: Clinical impact. J Hepatol 2018;68:268-79.

4. Cobbina E, Akhlaghi F. Non-alcoholic fatty liver disease (NAFLD) - pathogenesis, classification, and effect on drug-metabolizing enzymes and transporters. Drug Metab Rev 2017;49:197-211.

5. Robert O, Boujedidi H, Bigorgne A, et al. Decreased expression of the glucocorticoid receptor-GILZ pathway in Kupffer cells promotes liver inflammation in obese mice. J Hepatol 2016;64:916-24.

6. Xu C, Wan X, Xu L, et al. Xanthine oxidase in nonalcoholic fatty liver disease and hyperuricemia: One stone hits two birds. J Hepatol 2015;62:1412-9.

7. Carstensen-Kirberg M, Hatziagelaki E, Tsiavou A, et al. Sfrp5 associates with beta-cell function in humans. Eur J Clin Invest 2016;46:535-43.

8. Farrell GC, Van Rooyen D, Gan L, et al. NASH is an Inflammatory Disorder: Pathogenic, Prognostic and Therapeutic Implications. Gut Liver 2012;6:149-71.

9. Kaur S, Nag A, Singh AK, et al. PPAR $\gamma$-targeting Potential for Radioprotection. Curr Drug Targets 2018;19:1818-30.

10. Batatinha HA, Lima EA, Teixeira AA, et al. Association Between Aerobic Exercise and Rosiglitazone Avoided the NAFLD and Liver Inflammation Exacerbated in PPAR- $\alpha$ Knockout Mice. J Cell Physiol 2017;232:1008-19.

11. Wu CW, Chu ES, Lam CN, et al. PPARgamma is essential for protection against nonalcoholic steatohepatitis. Gene Ther 2010;17:790-8.

12. Sharma M, Mitnala S, Vishnubhotla RK, et al. The Riddle of Nonalcoholic Fatty Liver Disease: Progression From Nonalcoholic Fatty Liver to Nonalcoholic Steatohepatitis. 
J Clin Exp Hepatol 2015;5:147-58.

13. Machado MV, Diehl AM. Pathogenesis of Nonalcoholic Steatohepatitis. Gastroenterology 2016;150:1769-77.

14. Zhao C, Bu X, Wang W, et al. GEC-derived SFRP5 inhibits Wnt5a-induced macrophage chemotaxis and activation. PLoS One 2014;9:e85058.

15. Ouchi N, Higuchi A, Ohashi K, et al. Sfrp5 is an antiinflammatory adipokine that modulates metabolic dysfunction in obesity. Science 2010;329:454-7.

16. Gutiérrez-Vidal R, Vega-Badillo J, Reyes-Fermín LM, et al. SFRP5 hepatic expression is associated with nonalcoholic liver disease in morbidly obese women. Ann Hepatol 2015;14:666-74.

17. He L, Liu X, Wang L, et al. Thiazolidinediones for nonalcoholic steatohepatitis: A meta-analysis of randomized clinical trials. Medicine (Baltimore) 2016;95:e4947.

18. Lv C, Jiang Y, Wang H, et al. Sfrp5 expression and secretion in adipocytes are up-regulated during differentiation and are negatively correlated with insulin resistance. Cell Biol Int 2012;36:851-5.

19. Wei J, Bhattacharyya S, Jain M, et al. Regulation of Matrix Remodeling by Peroxisome Proliferator-Activated Receptor- $\gamma$ : A Novel Link Between Metabolism and Fibrogenesis. Open Rheumatol J 2012;6:103-15.

20. Cao Y, Gomes S A, Rangel E B, et al. S-nitrosoglutathione reductase-dependent PPAR $\gamma$ denitrosylation participates in MSC-derived adipogenesis and osteogenesis. J Clin Invest 2015;125:1679-91.

Cite this article as: Wang H, Li F, Feng J, Wang J, Liu X. The effects of S-nitrosylation-induced PPAR $\gamma /$ SFRP5 pathway inhibition on the conversion of non-alcoholic fatty liver to nonalcoholic steatohepatitis. Ann Transl Med 2021;9(8):684. doi: 10.21037/atm-21-1070
21. Yin R, Fang L, Li Y, et al. Pro-inflammatory Macrophages suppress PPAR $\gamma$ activity in Adipocytes via S-nitrosylation. Free Radic Biol Med 2015;89:895-905.

22. Salim T, Sershen CL, May EE. Investigating the Role of TNF- $\alpha$ and IFN- $\gamma$ Activation on the Dynamics of iNOS Gene Expression in LPS Stimulated Macrophages. PLoS One 2016;11:e0153289.

23. Chen LN, Sun J, Yang XD, et al. The Brain NO Levels and NOS Activities Ascended in the Early and Middle Stages and Descended in the Terminal Stage in ScrapieInfected Animal Models. Mol Neurobiol 2017;54:1786-96.

24. Zhang X, Li G, Guo Y, et al. Regulation of ezrin tension by S-nitrosylation mediates non-small cell lung cancer invasion and metastasis. Theranostics 2019;9:2555-71.

25. Pan L, Lin Z, Tang X, et al. S-Nitrosylation of Plastin-3 Exacerbates Thoracic Aortic Dissection Formation via Endothelial Barrier Dysfunction. Arterioscler Thromb Vasc Biol 2020;40:175-88.

26. Kaibori M, Okumura T, Sato K, et al. Inducible Nitric Oxide Synthase Expression in Liver Injury: Liver Protective Effects on Primary Rat Hepatocytes. Inflamm Allergy Drug Targets 2015;14:77-83.

27. Liman N, Alan E. Region-specific localization of NOS isoforms and NADPH-diaphorase activity in the intratesticular and excurrent duct systems of adult domestic cats (Felis catus). Microsc Res Tech 2016;79:192-208.

(English Language Editor: A. Kassem) 